\title{
Assessment of pollution of small rivers in urban areas (the case study of Barnaul city)
}

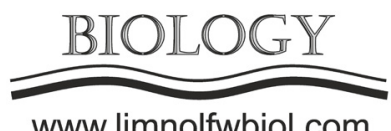

\author{
Podchufarova D.P.*, Ovcharenko E.A., Papina T.S.
}

Institute for Water and Environmental Problems, Siberian Branch of the Russian Academy of Sciences, Molodyozhnaya., 1, Barnaul, 656038, Russia

\begin{abstract}
The water pollution indices in the Barnaulka River were calculated based on the data of hydrochemical studies conducted in March, July, and October 2019. Based on the value of the water pollution index, the water quality in the river is estimated from «moderately polluted » to «very dirty» depending on the season and sampling locations. It was found that a significant contribution to the pollution of the Barnaulka River was made by the Pivovarka River, flowing only through the city.
\end{abstract}

Keywords: water pollution index, anthropogenic pollution, urban area, nutrients, small river.

\section{Introduction}

The water quality of the watersheds is formed under influence of both natural and anthropogenic factors. One of the reasons for the intensive decline of the quality of natural waters is the growth of anthropogenic impact and urbanization (Rotanova and Pupkova, 2013; Ternovaya et al., 2015). Small rivers located in industrial and densely populated areas are exposed to the most severe pollution. As a rule, they are more vulnerable to pollution and have a lower ability to natural purification. The Barnaulka River is a typical example of such water bodies.

Barnaulka - the left tributary of the Ob River flows through the Barnaul city. Features of the relief of the urban area are such that organized (through the storm sewer system) and diffuse surface runoff enters in the Barnaulka River, both directly and through its tributaries - Vlasikha River and Brewery River (Rotanova and Pupkova, 2013). For many years the main pollutants of Barnaulka are nutrients (ammonium, nitrites, phosphates) and some organic substances (Noskova et al., 2019).

The Altai Center for Hydrometeorology and Environmental Monitoring performs water quality of the Barnaulka River only at its mouth. Therefore, the purpose of this work is to assess of water pollution in the Barnaulka River, flowing through the city, using the water pollution index.

\section{Material and methods}

Sampling of water in the Barnaulka River was carried out in March, July and October 2019 at 8 points selected according to the increase of anthropogenic load (Fig.). Points 1-4 allow assessing the change of the hydrochemical characteristics of the river in the zone of predominantly low-rise buildings of the city. Point 4, located in $50 \mathrm{~m}$ above the mouth of the Pivovarka River, is the entry point into the zone with maximum anthropogenic load. Point 5 is the mouth of the Pivovarka River. Point 6 is located 180 $\mathrm{m}$ below the confluence of the Pivovarka River, which allows us to assess the contribution of this stream to the hydrochemical runoff of Barnaulka. The outlets of the city storm sewer system into the river are between points 7 and 8 . Point 8 is located $150 \mathrm{~m}$ above the mouth of the Barnaulka River and below of all storm water outlets.

Analysis of samples for hydrochemical indices was performed at the Chemical-Analytical Center of the Institute for Water and Environmental Problems Siberian Branch of the Russian Academy of Sciences. The calculation of the Water Pollution Index (WPI) was carried out according to 6 components (Glotova, 2006): oxygen and biochemical oxygen consumption $\left(\mathrm{BOC}_{5}\right)$ - mandatory, chemical oxygen consumption (COD), $\mathrm{NH}_{4}^{+}, \mathrm{NO}_{2}^{-}, \mathrm{PO}_{4}^{3-}-$ had the highest relative concentrations.

\section{Results and discussions}

Depending on the date and place of sampling, the WPM in the Barnaulka River varies over a wide range from 1.5 to 6.8 (Table). The maximum values of WPI are observed in the spring and autumn periods at the point 5 , and in the summer period at the point 7 . In autumn (October), at all sampling points (except point

*Corresponding author.

E-mail address: di.prant29@mail.ru (D.P. Podchufarova)

(C) Author(s) 2020. This work is distributed under the Creative Commons Attribution 4.0 License. 


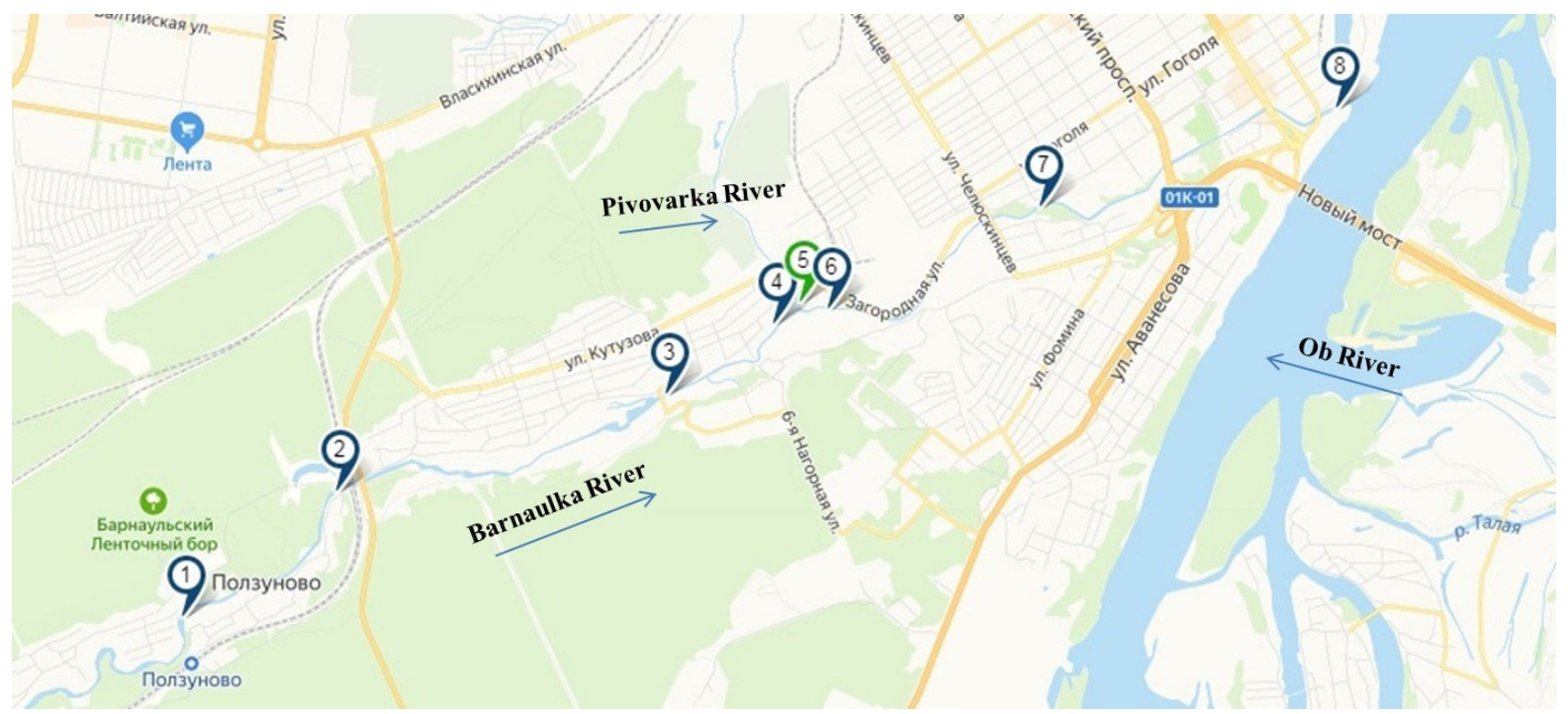

Fig. Map of sampling points on the Barnaulka River

5), the WPI value was the lowest. In the spring period, points 1-2 the most clearly shows the contribution to the pollution of the river low-rise buildings of the city. The Pivovarka River also has a significant impact on the pollution of the Barnaulka River.This is confirmed by the high value of WPI at the mouth of the Pivovarka River and its increase downstream of Barnaulka. A significant increase of WPI is observed after mouth of the Pivovarka River especially in the summer (July). On the contrary, in spring and autumn, the WPI differs insignificantly.

According to the value of WPI, the quality of water in the Barnaulka River is estimated from «moderately polluted» to «very dirty». In the spring, water quality changes in a chaotic manner: at first the quality class changes sharply from «dirty» (points 1-2) to «moderately polluted» (points 3-4), then there is a deterioration in water quality to « dirty» (point 5), then the quality water improves to «polluted» (points 6-12). In the summer and autumn periods, water quality class is assessed as «moderately polluted» at points 1-4, however it deteriorates to the «very dirty» already at the point 5 . Additionally, if in the autumn season at points 6-8 the water quality class again becomes «moderately polluted», then in the summer period there is a decrease of water quality to «very dirty» (point 7), with a slight improvement at the point 8 (class 4 ).

\section{Conclusions}

The study showed significant pollution of the Barnaulka River basin within the city. It was established that the WPI of the Barnaulka River varies over a wide range from 1.5 to 6.8. Depending on the season and place of sampling, the water quality class will vary from «moderately polluted» to «very dirty». A great contribution to the pollution of the Barnaulka River, especially in the summer, is made by its tributary - the Pivovarka River.

Table. Assessment of the class of water quality of the Barnaulka River

\begin{tabular}{|c|c|c|c|}
\hline Sampling points & \multicolumn{3}{|c|}{ Water Pollution Index (WPI) } \\
\cline { 2 - 4 } 1 & March & July & October \\
2 & $4.5^{5}$ & $2.0^{3}$ & $1.5^{3}$ \\
3 & $4.6^{5}$ & $2.2^{3}$ & $1.1^{3}$ \\
4 & $2.5^{3}$ & $2.3^{3}$ & $1.3^{3}$ \\
5 & $2.5^{3}$ & $2.1^{3}$ & $1.3^{3}$ \\
6 & $5.0^{5}$ & $6.0^{5}$ & $6.8^{6}$ \\
7 & $2.7^{4}$ & $5.8^{5}$ & $1.6^{3}$ \\
8 & $2.7^{4}$ & $6.4^{6}$ & $1.6^{3}$ \\
& $3.0^{4}$ & $3.1^{4}$ & $2.1^{3}$ \\
\hline Notation: Water Quality Class: & & \\
1 - very clean (less than 0,3); & & & \\
2 - clean (0,3 - 1); & & & \\
3 - moderately polluted (1 - 2,5); & & & \\
4 - polluted (2,5 - 4); & & & \\
5 - dirty (4 - 6); & & & \\
6 - very dirty (6 - 10); & & & \\
7 - extremely dirty (more than 10). & & & \\
\hline
\end{tabular}




\section{Acknowledgments}

This work was carried out at the ChemicalAnalytical Center of the Institute for Water and Environmental Problems of the SB RAS with financial support from the SB RAS project 134.1.2 «Spatialtemporal organization of aquatic ecosystems and assessment of the influence of natural and anthropogenic factors on the formation of hydrobiocenoses and surface water quality in the $\mathrm{Ob}$ basin and the Ob-Irtysh interfluve».

\section{References}

Glotova N.V. 2006. Monitoring sredy obitaniya [Habitat monitoring]. Chelyabinsk: Yuzhno-Ural'skiy State University Publishing House. (in Russian)
Noskova T.V., Podchufarova D.P., Lysenko M.S. et al. 2019. Environmental monitoring of the status of the Barnaulka River. Izvestiya Altayskogo Otdeleniya Russkogo Geograficheskogo Obshchestva [News of the Altai branch of the Russian Geographical Society] 4: 112-118. (in Russian)

Rotanova I.N., Pupkova V.V. 2013. Small rivers of the urban territory as conservation objects of the urbanized environment (research experience on the example of Barnaul). Geografiya i Prirodopol'zovaniye Sibiri [Geography and Nature Management of Siberia] 15: 171-181. (in Russian)

Ternovaya L.V., Skripnik A.V., Kolomoets S.Yu. 2015. Ecological monitoring of small water bodies. Vestnik Altayskogo Gosudarstvennogo Agrarnogo Universiteta [Bulletin of the Altai State Agrarian University] 8: 53-57. (in Russian) 